\title{
Sociedade sensoriada:
}

\section{a sociedade da transformação digital}

\section{MARCos CESAR WEISS ${ }^{I}$}

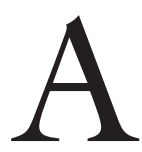

O LONGO DO TEMPO, as sociedades evoluíram de padrões de organização simples, como as tribos de coletores e caçadores, e posteriormente as aldeias rurais, para padrões mais complexos que originaram as vilas, e depois as cidades. Novos padrões sociais e culturais, novas formas de produção e comércio, de interações e colaborações, assim como novos códigos de conduta e leis, novas organizações de comando e controle e de participação também evoluíram ao longo do tempo. Esses ciclos de evolução das formas de organização social foram motivadores para e motivados pelo surgimento de tecnologias. Os aquedutos romanos ou os sistemas de esgoto londrinos; as forjarias de aço ou as injetoras de plástico; os motores a vapor ou os elétricos; as lâmpadas incandescentes ou as de LED; o rádio, o automóvel, para além de outras tantas que, a seu tempo, buscaram atender as demandas mais elementares das sociedades, moldaram o que somos hoje, criando, promovendo e fortalecendo diferentes formas de socialização.

Nas últimas décadas, particularmente após as guerras mundiais, vimos uma profusão de inovações. Particularmente assistimos ao advento dos microprocessadores, da fibra ótica e, principalmente, da internet. Vivemos agora mais uma era de profundas transformações sociais e tecnológicas, ambas significativamente estimuladas principalmente pela incessante e crescente geração de inovações em Tecnologias da Informação e Comunicação (TIC). Uma era em que uma nova sociedade parece estar emergindo a partir da tão alardeada e transformação digital.

A vida humana tem sido marcada pelas novidades, pelas mudanças, decorrentes de sua inegável inventividade. Hoje nos encontramos e nos relacionamos no mundo virtual. Já não nos reunimos em torno da fogueira ou ao pé do rádio, como faziam nossos antepassados. Nossas fogueiras e rádios agora se chamam redes sociais e tudo sugere que não poderemos delas nos desvencilhar sem danos.

De certo, o determinismo tecnológico postulado por Thorstein Veblen no século XIX não é o que basta para que a sociedade floresça, como que num mundo em que as exigências sociais e políticas não se conformem como fatores essenciais para o seu prosseguimento. Nada mais equivocado. Ao contrário, como afirma um dos principais críticos da Teoria do Determinismo Tecnológico, o professor Andrew Feenberg, professor de Filosofia da Tecnologia na 
Simon Fraser University (SFU), Canadá, os valores, a cultura, a história e as próprias necessidades da sociedade devem ser os estimuladores e razões suficientes para que novas tecnologias possam ser desenvolvidas e sustentadas ao longo do tempo, não se afirmando, portanto, que os avanços e os desenvolvimentos de novas tecnologias determinam e influenciam a dinâmica social ao ponto de serem consideradas causa e não efeito (Feenberg, 2010). É de supor que, não fossem essas demandas - em todos os seus matizes, necessárias ou tão somente desejáveis -, aspectos como restrições legais, políticas e religiosas, de custos e até mesmo potencias intervencionismos governamentais poderiam inibir o espírito criativo, inovador e empreendedor dos indivíduos e das organizações.

As TIC têm se conformado como vetores vitais para que inovações aconteçam em todas as áreas da atividade humana, e isso inclui a criação de possibilidades e instrumentos para que empresas e indivíduos se relacionem entre si. Elas permitem que informações de toda natureza atravessem fronteiras, aproximando o que está geograficamente distante (Boschma, 2005) e estejam disponíveis praticamente em tempo real, alicerçando e promovendo diferentes formas de colaboração científica, tecnológica, comercial, legal, institucional, política ou cultural.

Nessa direção, ao criar, promover e difundir a economia da informação, a partir de um ecossistema globalmente acessível, a sociedade passa a experimentar um novo desafio: acrescentar inteligência e novas dinâmicas de uso da informação, de forma que amadureça e volte como conhecimento capaz de gerar mais e mais valor para essa mesma sociedade. Com isso, novas demandas surgem. A economia deixa de operar em tempo parcial para se transformar em uma economia que opera 24 horas por dia, durante sete dias por semana. Governos passam a estar sob influência e vigilância direta da sociedade local e global, sendo constantemente percebidos, avaliados e desafiados em suas estruturas institucionais, políticas e sociais, para além da publicidade que podem e devem dar sobre suas decisões particulares e multilaterais. A cultura tem suas normas e valores coletivos expostos, dando publicidade às escolhas que são feitas em termos de identidade e convicções. As pessoas, particularmente, são confrontadas com situações de incerteza em quaisquer dimensões da vida, mesmo quando isso envolve suas opções de vida afetiva ou suas opiniões e escolhas políticas.

A sociedade da informação está em constantes e radicais mudanças, resultado da própria constância de mudanças na vida de cada organização e de cada indivíduo particularmente (Pintér, 2003). Até então, essa sociedade tem sido o resultado do trabalho de pesquisadores, da indústria e de governos que, ao transformar informação em conhecimento, desenvolveram, encorajaram e implementaram tecnologias e processos capazes de difundir informações em qualquer lugar e a qualquer tempo. Mostraram a extraordinária capacidade de inovação em TIC e o papel crucial que essas tecnologias têm em trazer convergência para a geração de mais e mais inovações. 
As tecnologias tornam os custos de reprodução das informações insignificantes, criando um paradoxo sobre como financiar os custos da produção inicial. A atual onipresença computacional - conhecida por computação ubíqua ou pervasiva, caracterizada, basicamente, pela convergência de dispositivos móveis, aplicativos, comunicação sem fio e internet (Weiser, 1999) - se reflete na sociedade contemporânea como uma importante força para constituição de novas formas de interação, cooperação e colaboração e, consequentemente, impulsionando mais e mais conhecimentos.

Nesse contexto, dois aspectos merecem reflexão. O primeiro diz respeito à capacidade que a sociedade tem em identificar, produzir, selecionar, adaptar, comercializar e utilizar informações. Essa capacidade é crítica para a construção e aplicação de conhecimentos que visem ao desenvolvimento humano e ao crescimento sustentável da economia, com visão inequívoca de empoderamento social que envolva pluralidade, inclusão, solidariedade e participação (Unesco, 2005). Outro aspecto diz respeito à contínua proliferação de tecnologias que vão se tornando cada vez mais importantes na vida das pessoas e das organizações e se tornando onipresentes em todos os aspectos da dinâmica social, a despeito de temas que potencializam riscos à sociedade do conhecimento - privacidade, segurança, complexidade, liberdade de expressão, propriedade intelectual, fratura digital, mudanças no processo de educação, questões de gênero, diversidade cultural, autonomia, dependência e confiança.

Na visão de Aikenhead, Orpwood e Fensham (2011), o valor da sociedade do conhecimento está associado com o saber aprender, saber como continuar a aprender e saber quando é preciso saber mais, ao invés de conhecer muitos pedaços de conteúdo de um currículo genérico; saber aprender com os outros e não apenas acumulando conhecimento como um indivíduo; usar o conhecimento como um recurso para resolução de problemas ao invés de simplesmente usá-lo como um catálogo de respostas certas; e promover o desenvolvimento de competências importantes para a geração de mais conhecimentos e não apenas guardá-los. Ela é, portanto, capaz de conhecer, entender mecanismos e com isso atuar efetivamente na dinâmica social; estabelecer novas formas de interação nos mercados e nas relações entre poder público, organizações e cidadãos; demandar e estimular as atividades de pesquisa, desenvolvimento e inovação; desenvolver, implementar e manter novas práticas de gestão pública e privada, que privilegiem as demandas básicas da sociedade, como saúde, educação, emprego, alimentos, segurança e lazer, influenciado positivamente os ambientes de negócio e a qualidade de vida das pessoas.

As TIC têm possibilitado o acesso e o compartilhamento à informação quase que em tempo real. Essa velocidade também tem sido experimentada na disseminação do conhecimento que há pouco permanecia adormecido por longos períodos de tempo nos centros de pesquisa ou mesmo na indústria, até chegar a quem dele desejasse se apropriar, agora é disponibilizado de forma pra- 
ticamente instantânea. Ao redor do globo, pesquisadores, em todos os campos do saber, seja na academia, seja na indústria, podem compartilhar seus achados, acelerando e incrementando as capacidades de geração e de compartilhamento de mais e mais conhecimentos, determinando uma nova dinâmica social global. A alta intensidade de transmissão e difusão de conhecimentos observada atualmente ocorre porque sua produção é muito mais rápida do que em outros tempos. Mais do que isso, porque a sociedade está cada vez mais ávida por mais e novos conhecimento.

Nessa sociedade do conhecimento, crescimento e desenvolvimento econômicos se manifestam como prioridades em quaisquer texturas políticas e econômicas, assim como prioritárias são as iniciativas para a redução das externalidades negativas decorrentes deles: poluição do ar e das águas, redução e mau uso dos recursos naturais estratégicos, crescimento demográfico e desemprego. É fundamental que a sociedade do conhecimento promova a paz e a sustentabilidade, garantindo que decisões, em todos os níveis da sociedade, sejam direcionadas à confluência do conhecimento em benefício das pessoas, tendo em conta a prosperidade econômica, a equidade e justiça social e a preservação ambiental (Haller, 2012). Ademais, o desenvolvimento humano e a abordagem centrada no seu empoderamento, implícitos no conceito de sociedade do conhecimento, devem garantir que os direitos humanos e as liberdades fundamentais estejam implementadas mais plenamente, ao mesmo tempo que buscam maior eficácia na luta contra a pobreza e na formulação de políticas de desenvolvimento (Unesco, 2005).

A sociedade do conhecimento demanda cada vez mais complexas infraestruturas e sistemas para que toda informação seja armazenada, organizada e distribuída, permitindo que estejam acessíveis seguindo determinados padrões e convenções, inteligíveis para qualquer pessoa (Poonia; Bhardwaj; Dangayach, 2009). Ela é, assim, fortemente caracterizada pela possibilidade de compartilhamento de dados e informações, de forma mais rápida e através de longas distâncias: computadores potentes e mentes bem educadas, juntos, para criar riqueza (Goede, 2011).

Os investimentos em TIC surgem como uma abordagem interdisciplinar consistente para o desenvolvimento econômico e para a redução das desigualdades, visto terem o potencial de habilitar as pessoas à participação ativa na sociedade, desde que esteja presente um arcabouço legal capaz de proteger os direitos a liberdade de expressão, liberdade de informação e um ambiente regulatório de proteção à privacidade. Esse último aspecto tem profunda relevância nesses tempos de transformação digital: nas dinâmicas sociais onde a informação assume papel de significativa importância, os modelos institucionais convencionais podem não estar preparados para conviver com o novo paradigma informacional onde a informação, uma vez produzida, está pronta para ser divulgada e mantê-la restrita de outros requer consideráveis esforços. 
As reflexões trazidas até aqui sugerem que as TIC têm promovido impactos significativos na sociedade, promovendo o surgimento de novos conteúdos e a recriação de novas formas de interação. Os avanços nessa área têm se destacado como importantes vetores para o incremento da vida social, tanto nas suas dimensões materiais como nas imateriais (lúdicas, pessoais e imaginárias). Comunidades virtuais se reúnem ao redor de interesses particulares ou de temas regionais ou globais de maior ou de menor repercussão, determinando a criação fronteiras virtuais que extrapolam as fronteiras geográficas.

Ao retratar e refletir sobre essas poucas décadas de espraiamento da internet na sociedade moderna, Vieira (2006, p.4) afirma:

O tempo-espaço social na pós-modernidade ganhou novas significâncias com a rápida evolução das técnicas microeletrônicas. $\mathrm{O}$ tempo-espaço cibernético foi produzido por tecnologias evolutivas em realidades antecedentes. Na verdade, o mundo real é o mundo da existência viva e nela a espécie humana é produtora permanente de novas realidades. O cibernético é uma realidade que flui pelas cibervias e se concretiza na virtualidade de imagens, signos e símbolos. Ao formar imagens e significados, o virtual se torna uma forma de realidade que opera mensagens instantâneas numa extraordinária compressão do tempo-espaço. No mundo cibernético não há mais tempo longo e distância longa, mas o tempo instantâneo e a presença virtual. O tempo virtual coloca em temporalidade espaços distantes, produzindo efeitos concomitantes aos fluxos econômicos, sociais, políticos e culturais.

A sociedade contemporânea potencializa o uso das TIC como forma de comunicação e de interação, derivando da racionalidade física e da objetividade uma forma singular de subjetividade que vai do emocional ao festivo. Essa sociedade cibernética, descrita por Jensen, Danziger e Venkatesh (2007, p.41) como "aquela onde ocorrem interações entre e com uma série de grupos online que são caracterizados por diferentes graus de anonimato e vínculos afetivos e que navegam na internet todos os dias", tem crescido e se projetado de maneira formidável. Ela está em todos os lugares e a qualquer tempo "curtindo" e se engajando em manifestações, discussões, ações e movimentos de toda natureza, de norte a sul, de leste a oeste do planeta, tanto para o lado positivo como para o negativo.

O relatório "Global Internet Report 2014 - Open and Sustainable Access for All" (Kende, 2014, p.8), publicado pela Internet Society, traz uma reflexão relevante sobre esse fenômeno:

A internet tem mudado o mundo. $\mathrm{O}$ acesso aberto à internet tem revolucionado a forma como os indivíduos se comunicam e colaboram, como empreendedores e corporações conduzem seus negócios e como governos e cidadãos interagem. Ao mesmo tempo, a internet estabeleceu um modelo revolucionário para seu próprio desenvolvimento e governança, abrangendo todas as partes interessadas. 
Desde o início de sua exploração em regime produtivo e comercial, a partir de 1990, embora o início das pesquisas e desenvolvimentos datem dos anos $1960,{ }^{1}$ a internet tem se constituído em importante instrumento de mudanças globais. No contexto da sociedade cibernética, para além de todos os outros avanços conhecidos das TIC, o advento e a difusão da internet fazem dela um canal para o estreitamento das relações humanas e para o incremento das capacidades organizacionais, facilitando o fluxo de informações e de conhecimento, configurando-se como uma ferramenta indispensável para muitos setores da economia e para as pessoas em particular. A vasta quantidade de informações e conhecimentos disponíveis na internet, acessíveis de forma rápida e fácil por meio de mecanismos de busca e byperlinks, incrementa cada dia mais a quantidade de pessoas e organizações que a ela recorrem para resolver suas demandas, proporcionando significativos ganhos de eficiência, reduzindo a necessidade de deslocamento de pessoas a postos de atendimento de toda sorte de serviços públicos ou privados, para além de promover a intensificação da inteligência necessária para a atuação no atual contexto econômico.

Para Koles e Nagy (2014, p. 290), citando Bardzel e Odom (2008) e Lemma (2010), "o mundo virtual tende a ser percebido como ambientes integrados e simbólicos para os quais os indivíduos rendem significado especial, uma vez que oferecem experiências únicas e potenciais que diferem substancialmente da existência off-line de sua base como usuários". Assim, no mundo cibernético, pessoas e organizações podem fazer o que quiserem, de forma virtual, como no mundo real ou com mais (pretensa) liberdade. Se, por um lado, elas encontram pessoas, discutem assuntos, compartilham ideias e conhecimentos, fazem negócios, marcam posições e visões, por outro, elas podem também cometer crimes e até mesmo propagar o terrorismo com apenas alguns clicks de mouse.

O desafio que se impõe, então, está justamente assentado sobre como enfrentar situações avessas à ética, ao progresso e ao bem-estar das pessoas, organizações e instituições. Eventos como roubo de identidades, fraudes, pornografia infantil, violação aos direitos intelectuais e de propriedade, e toda sorte de negação de serviços eletrônicos, que causam perdas financeiras e de credibilidade e, em algumas situações extremas, provocam perdas humanas, são realidades para as quais não se pode virar as costas. O fato é que aquilo que não é aceitável no mundo real também não o deveria também ser no mundo virtual. A sociedade cibernética fortemente calcada nas TIC, tal como discutido até esta altura, é uma realidade e se encontra em permanente expansão.

Agora, parece, vamos em direção a uma nova forma de arranjo social, ainda graças aos progressos feitos nas TIC. Se a inovação é a criação de novas realidades (Plonski, 2017), as TIC permanecem configurando novas realidades.

Estamos ligados à internet de forma inexorável. Dados da International Telecommunication Union (ITU) de 2016, dão conta que já ultrapassamos a marca dos 3 bilhões de pessoas que usam a internet em todo o planeta. Muitas 
delas dominam plenamente os seus recursos ou estão sendo educadas e formadas com o seu uso, e esse fato as tem tornado significativamente mais exigentes e críticas com o que diz respeito às possibilidades de verem suas necessidades atendidas por esse meio. É fundamental atentar para o fato de que todo o potencial de oferta de serviços de conveniência pela internet é incrementado graças ao advento dos dispositivos móveis, que possibilitam a experiência da navegação na internet a qualquer hora, em qualquer lugar.

Flexibilidade, conveniência, produtividade e qualidade de serviços são, portanto, o que se pode esperar de qualquer organização que busque se projetar na internet, incluindo o poder público. $\mathrm{O}$ advento e a adoção crescentes dos telefones inteligentes e outros dispositivos móveis de comunicação e interação têm servido como importantes instrumentos para viabilizar e estreitar a relação entre as pessoas e o mundo onde vivem. Com o crescimento da presença desses dispositivos e dos avanços em telecomunicações, a cada dia surgem novas possibilidades de aplicativos para equipá-los e transformá-los em dispositivos mais inteligentes, transformando cada usuário em uma verdadeira e inequívoca fonte de geração de dados e consumidora de informações. Para além das facilidades de comunicação por voz, esses dispositivos têm proporcionado uma nova forma de interação, com novas formas de percepção e de registro da realidade espaço temporal.

Se em tempos nem tão remotos certas condições das cadeias produtivas, ou mesmo da vida urbana, eram percebidas de forma reativa e baseadas em eventos perceptíveis por instrumentos mecânicos ou pela ação humana, a dimensão espaço-temporal momentânea se reveste de capacidades virtuais e materiais capazes de antever eventos, prever consequências e antecipar decisões antes mesmo que outros eventos, de maiores ou menores consequências, positivas ou negativas, possam ocorrer. A proliferação de sensores, incorporados e distribuídos em toda sorte de lugares e bens, tem marcado o surgimento de uma nova e diferente forma de interatividade. Em poucas décadas de evolução das tecnologias derivadas particularmente da eletrônica, muitas inovações foram incorporadas à vida cotidiana da humanidade.

Da perspectiva do indivíduo, ações, movimentos, interações, comunicações, condições de ambiência, sinais vitais e uma infinidade de eventos podem ser automaticamente capturados e armazenados de forma que possam ser recuperados para construir ou reconstruir o ritmo e a face da dinâmica social. Já não nos separamos de nossos dispositivos móveis e deles dependemos para praticamente qualquer coisa: guiamo-nos pelo Waze, pedimos nossa comida pelo iFood, realizamos nossas transações bancárias com nosso e-banking enquanto baixamos a play list preferida do Spotfy e nossos sinais vitais são monitorados por algum aplicativo. Nossas casas, nossos automóveis, nossos televisores, nossos relógios, nossos pets estão conectados à internet. Nossos calçados e roupas já vão na mesma direção. Nossa localização geográfica, o que fazemos no mundo real e o que fazemos no mundo virtual já não são coisas tão protegidas dos olhos alheios. 
Da perspectiva do lugar, espaços e prédios públicos ou privados, máquinas e plantas produtivas, redes de geração e transmissão de energia, sistemas de saneamento e abastecimento de água, escolas, hospitais, segurança pública, meios de transporte públicos e privados, com extrema capacidade de conexão entre si por meio do mundo virtual, têm sido providos de artefatos eletrônicos capazes de promover uma profusão de dados, informações e conhecimentos, passando a influenciar diretamente a dinâmica urbana e a forma como a vida social se realiza, imprimindo à ela uma nova forma de inteligência.

Ainda não começamos a viver e sentir plenamente os efeitos sociais e econômicos da Internet of Thinks (IoT) - o lugar virtual onde toda sorte de dispositivos, nas mais diferentes áreas de aplicação e em quaisquer lugares onde estejam, está interconectada por meio da internet, interagindo e eventualmente alterando suas formas de funcionamento (Atzoria; Ierab; Morabito, 2017). Os chamados bio chips (Saxena; Kumar, 2018) já são realidade nesse mundo de constantes e inconstantes transformações tecnológicas e sociais; já fazemos parte da internet das coisas ou mesmo já podemos, provavelmente, ser as coisas da internet.

Rumamos em direção a novos paradigmas. Assim como as redes locais industriais - Industry 4.0 - estão ofuscando os paradigmas atuais da internet como a conhecemos, a Internet of Skills - Human 4.0 - se conformará como um novo paradigma, possibilitando a "entrega de experiências físicas remota e globalmente, revolucionando as operações e as capacidades de serviços das indústrias e a maneira como ensinamos, aprendendo e interagimos com o meio" (Dohler et al., 2017). Ou ainda pelo paradigma da Internet of People (IoP), "um complexo sistema sociotécnico onde os seres humanos, com seus dispositivos pessoais, são os principais nós da rede [...] os dispositivos de usuário tornam-se proxies de seus usuários no mundo cibernético: eles se comunicam, trocam e gerenciam dados em nome de seus usuários e devem se comportar da maneira que seus usuários humanos fariam se interagissem no mundo físico", articulado por Conti, Passarella e Das (2017). ${ }^{2}$

A largos passos, a sociedade dos sensores, postulada por Andrejevic e Burdon (2015), começa a dar lugar a uma sociedade que chamo de sociedade sensoriada.

Nessa nova sociedade, cada indivíduo - que lida com fatos de um tempo presente que se confundem com um tempo futuro que de alguma forma pode ser previsto - terá um sensor embarcado em si e sem o qual pouco ou nada poderá fazer no mundo interconectado, interferindo dramaticamente em sua vida cotidiana. No presente-futuro, a sociedade sensoriada terá seus dados formidavelmente coletados e explorados pela ciência de dados e que se tornarão consistentes insumos para que tecnologias baseadas em inteligência artificial realizem de forma autônoma muito mais do que hoje podemos ter com os chamados bots ou com algumas aplicações baseadas em sistemas especialistas. Provavelmente, 
nossas condições de humor nos dias seguintes poderão ser antecipadas para que alguém decida sobre oferecer ou não um produto ou sobre a possibilidade de sermos acometidos por um mal súbito e termos socorro no instante que antecede o fato ou mesmo sobre nossas intenções em escrever algum paper, retratando dias e noites de esforço em pesquisa, e que serão materializadas num formato tão próximo daquilo que desejávamos expressar que ficaremos surpresos ao ponto de duvidarmos quem realmente tem inteligência artificial.

A nova geração de empresas intensivas na utilização de TIC, as chamadas tech (fintech, insurtech, healthtech, edutech, lawthech, etecetera-tech), poderá ter também as peopletech, que se valerão dos dados provenientes de sensores embarcados nos indivíduos e capazes de refletir dúvidas e sentimentos e comportamentos e expectativas do tempo presente-futuro desses indivíduos e que se unirão aos dados globais para que, como num círculo virtuoso (ou vicioso), mais conhecimentos sejam produzidos.

A sociedade sensoriada não é um exercício de futurismo, mas a materialização do futuro no presente. No tempo presente-futuro, já vai contribuindo de forma espetacular para o surgimento de novas redes de colaboração entre os diferentes atores sociais, localizados em diferentes geografias; para que as empresas implementem inovações em seus processos de produção e entrega de bens e serviços; para a criação de novas demandas que exigirão o desenvolvimento de novas habilidades e competências, gerando oportunidades de trabalho no mundo real e, particularmente, no mundo virtual; para que a gestão e entrega das infraestruturas e dos serviços públicos esperados seja realizada com maiores níveis de transparência e eficiência.

Como em todo e qualquer momento na história da vida humana, a sociedade sensoriada também fará e interporá desafios a ela mesma: vigilância, privacidade, direito de propriedade, governança e capacidades técnicas e humanas para lidar com grandes volumes de dados e informações, para além da vida pessoal inviolável, merecerão mais e mais reflexões em um ambiente "extrassensores", se tal for possível. O dilema de Minority Report, ${ }^{3}$ provavelmente, será palco de discussões.

Podemos negar o passado, mas não podemos evitar o presente-futuro. A sociedade sensoriada, a despeito de controvérsias e discussões que possa despertar, vai determinar a gênese de uma nova forma de interação entre os indivíduos e o meio, em todos os campos do que acreditamos hoje ser o conhecimento.

\section{Notas}

1 De acordo com a publicação "Brief History of the Internet", disponível em: <http:// www.internetsociety.org/internet/what-internet/history-internet/brief-history-internet>.

2 No texto original em inglês, os autores justificam: "This is because people are no longer mere users of network technologies and services, designed exclusively with engineering 
optimization parameters in mind, but their behavior becomes one of the key elements for designing all facets of the Internet technologies. Therefore, the algorithms and protocols for IoP networking and data exchange are not driven exclusively by the need to optimize network resource usage (as in the design of legacy Internet systems) but are quantitatively modeled and considered as a first-class design parameter in order to cater to the human needs" (Conti; Passarella; Das, 2017, p.17).

3 Minority Report é um filme de ficção científica neo-noir lançado em 2002 e dirigido por Steven Spielberg. O roteiro é baseado no conto de mesmo nome de Philip K. Dick. A história se desenvolve Washington (DC) e Northern Virginia, Estados Unidos, no ano 2054, onde "Pré-Crime", um departamento de polícia especializada, apreende criminosos com base no conhecimento prévio fornecido por três videntes chamados precogs. O tema central do filme é a questão do livre arbítrio contra o determinismo, examinando se o livre arbítrio pode existir se o futuro está definido e conhecido antecipadamente. Outros temas incluem o papel preventivo do governo na proteção de seus cidadãos, o papel da mídia em um estado futuro em que os avanços tecnológicos tornam a sua presença quase sem limites, a legalidade potencial de um promotor infalível (Disponível em: <https://goo.gl/nQB9ZB>).

\section{Referências}

AIKENHEAD, G. S.; ORPWOOD, G.; FENSHAM, P. Scientific literacy for a knowledge society. In: LINDER, C. et al. (Ed.) Exploring the landscape of scientific literacy. New York: Routledge, Taylor and Francis Group, 2011. p.28-44.

ANDREJEVIC, M.; BURDON, M. Defining the Sensor Society. Television and New Media, v.16, n.1, p.19-36, 2015.

ATZORIA, L.; IERAB, A.; MORABITO, G. Understanding the Internet of Things: definition, potentials, and societal role of a fast evolving paradigm. Ad Hoc Networks, v.56, n.1, p.122-40, 2017.

BARDZEL, S.; ODOM, W. The experience of embodied space in virtual worlds: an ethnography of a second life community. Space and Culture, v.11, n.3, p.239-59, 2008.

BOSCHMA, R. A. Proximity and innovation: a critical assessment. Regional Studies, v.39, n.1, p.61-74, 2005.

CONTI, M.; PASSARELLA, A.; DAS, S. K. The Internet of People (IoP): A new wave in pervasive mobile computing. Pervasive and Mobile Computing, v.41, p.1-27, 2017.

DOHLER, M. et al. Internet of skills, where robotics meets AI, 5G and the Tactile Internet. In: EUROPEAN CONFERENCE ON NETWORKS AND COMMUNICATIONS (EUCNC), Anais eletrônicos... p.1-5, 2017. Disponível em: <https://ieeexplore.ieee.org/document/7980645/>. Acesso em: 6 jun. 2018.

FEENBERG, A. Racionalização subversiva: tecnologia, poder e democracia. In: NEDER, R. T. (Org.) A teoria critica de Andrew Feenberg: racionalização democrática, poder e tecnologia. Brasília: Observatório do Movimento pela Tecnologia Social na América Latina / CDS / UnB / Capes, 2010. cap.2. p.69-95.

GOEDE, M. The wise society: beyond the knowledge Economy. Foresight, v.13, n.1, p.36-45, 2011. 
HALLER, A. P. Economic Growth in Knowledge-Based Society. Economics, Management, and Financial Markets, v.7, n.4, p.517-25, 2012.

ITU - INTERNATIONAL TELECOMMUNICATION UNION. Statistics. 2016. Disponível em: <https://www.itu.int/en/ITU-D/Statistics/Pages/stat/default. aspx>. Acesso em: 20 abr. 2018.

JENSEN, M. J.; DANZIGER, J. N.; VENKATESH, A. Civil Society and Cyber Society: The Role of the Internet in Community Associations and Democratic Politics. The Information Society, n.23, p.39-50, 2007.

KENDE, M. Global Internet Report 2014 - Open and Sustainable Access for All. Internet Society, 2014. Disponível em: <https://www.internetsociety.org/globalinternetreport $/ 2014 />$. Acesso em: 4 mar. 2015.

KOLES, B.; NAGY, P. Individual and Professional Development in the Digital Age: Towards a Conceptual Model of Virtual Worlds for Organizations. Management Research Review, v.37, n.3, p.288-307, 2014.

LEMMA, A. An order of pure decision: growing up in a virtual world and the adolescent's experience of being-in-a-body. Journal of American Psychoanalytical Association, v.58, n.4, p.691-714, 2010.

PINTÉR, R. Conceptualizing Information Society as Risk Society. Periodica Polytechnica Social and Mananagement Sciences, v.11, n.1, p.35-44, 2003.

PLONSKI, G. A. Inovação em transformação. Estudos Avançados, v.31, n.90, p.7-21, 2017.

POONIA, A. S.; BHARDWAJ, A.; DANGAYACH, G. S., Ethical Values and Practices for Cyber Society. In: INTERNATIONAL CONFERENCE OF CURRENT TRENDS IN INFORMATION TECHNOLOGY (CTIT), Anais eletrônicos... p.1-5, 2009. Disponível em: <http://goo.gl/zXvSbY>. Acesso em: 4 abr. 2018.

SAXENA, S. K.; KUMAR, U. Nanotechnology applications to telecommunications and networking. International Journal of Academic Research and Development, v.3, n.2, p.1584-6, 2018.

UNESCO. Towards Knowledge Societies. 2005. Disponível em: <http://unesdoc.unesco.org/images/0014/001418/141843e.pdf>. Acesso em: 25 ago. 2017.

VIEIRA, E. F. A Sociedade Cibernética. Cadernos EBAPE.BR, v.4, n.2, p.1-10, 2006.

WEISER, M. The Computer for the 21 st Century. Mobile Computing and Communications Review - Special issue dedicated to Mark Weiser, v.3, n.3, p.3-11, 1999.

RESUMO - As tecnologias têm moldado a sociedade ao longo do tempo. Contemporaneamente, as inovações em Tecnologias da Informação e Comunicação (TIC) têm impulsionado uma nova e intensa transformação nomeada como transformação digital. A partir dessas constatações, o artigo busca refletir sobre o poder exercido por essas tecnologias sobre a sociedade até o ponto de se vislumbrar o advento de uma sociedade caracterizada por sua inseparabilidade da tecnologia: a sociedade sensoriada.

PALAVRAS-CHAVE: Cidade, Sociedade sensoriada, Transformação digital. 
ABSTRACT - Technologies have shaped society over the time. Presently, innovations in information and communication technologies (ICT) have driven a new and intense transformation known as digital transformation. Based on these observations, this paper aims to reflect on the power these technologies exert upon society to the point that one glimpses the advent of a society characterized by its inseparability from technology: the sensor ized society.

KEYWORDS: City, Sensor-ized society, Digital transformation.

Marcos Cesar Weiss é doutor em Administração, professor na Escola Superior de Propaganda e Marketing (ESPM) e no Laboratório de Sustentabilidade de Escola Politécnica da USP (Lassu). Fundador da RACI - Rede Acadêmica para Cidades Inteligentes.

@ - mw@marcosweiss.com.br / https://orcid.org/0000-0002-4879-3543

Recebido em 18.7.2018 e aceito em 29.11.2019.

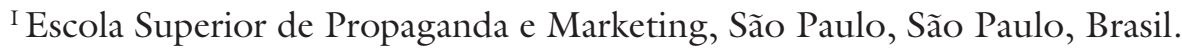

